\title{
Functional Test for Fetal Brain: The Role of KANET Test
}

\author{
Panagiotis Antsaklis, Asim Kurjak, Sebija Izetbegovic
}

\begin{abstract}
Defining normal and abnormal fetal neurological function in utero in order to better predict antenatally which fetuses are at risk for adverse neurological outcome has remained a great challenge in perinatal medicine. Fetal behavioral patterns have been considered as indicators of fetal brain development. It has been suggested that the assessment of fetal behavior in different periods of gestation may make possible the distinction between normal and abnormal brain development. Advances in ultrasound technology and particularly the introduction of real time four-dimensional (4D) ultrasonography, allowed direct observation of in utero life and offered a new insight for the assessment of fetal behavior. Fetal behavioral movements, the full range of facial expressions and mobility of fetal upper and lower extremities and fingers can be clearly visualized with 4D ultrasound. A new scoring system for the assessment of fetal neurobehavior based on prenatal assessment of the fetus with 4D sonography has been developed based on the same technique that neonatologists assess newborns during the first days of their postnatal life. This overview focuses on the study of fetal behavior and neurological assessment with 4D ultrasound.
\end{abstract}

Keywords: Fetal neurology, Neurobehavior, Four-dimensional ultrasound, KANET.

How to cite this article: Antsaklis $P$, Kurjak $A$, Izetbegovic $S$. Functional Testfor Fetal Brain: The Role of KANET Test. Donald School J Ultrasound Obstet Gynecol 2013;7(4):385-399.

Source of support $\mathrm{Nil}$

Conflict of interest: None declared

\section{INTRODUCTION}

Fetal behavior is assessed through direct observation of movements and activities of the fetus in utero, with the use of ultrasound machines. ${ }^{1-3} \mathrm{~A}$ dvances of technology and especially of three-dimensional (3D) and four-dimensional (4D) ultrasound, have given the opportunity to study in real time and with explicit detail fetal anatomy and fetal activity. Studies have shown that there is a specific fetal behavioral pattern that corresponds to each week or trimester of inutero life and that this behavioral pattern reflects the process of human brain development and maturation. ${ }^{4}$ The anatomic and functional development of the human brain is a uniquely complex and long lasting procedure that goes through very strict developmental stages, which starts from the second month of gestational age and continues up to adult life. ${ }^{4}$ Development of the human brain is still incomplete at the end of in utero life and continues for decades after birth. The most important steps of human brain development are shown in Table 1. Human brain development is a very structured and detailed procedure, but as such it is at the same time very sensitive and susceptible to a wide variety of factors and defects, that may occur during any of the phases of intrauterine life. In cases of extremely premature neonates the brain development exutero is unable to follow the genetically programmed growth pattern that the brain should have in utero, even when the postnatal environment and feeding mimics the conditions of in uterolife. ${ }^{5,6} \mathrm{G}$ enetic factors, external stimuli, pathological conditions or even environmental changes, can affect the fetal human brain up to a degree that may be difficult to assess, especially prenatally. In many cases we are unable to detect fetal brain impairment, and even when we suspect it, again we are often unable to say in what way and to what extent will the fetus be affected. B rain injuries can occur prenatally, perinatally and/or even postnatally or neonatally. The neurological compromises that may result from such insults, may present with a wide variety of clinical pictures, ranging from mild behavioral and learning disabilities to severe cerebral palsy (CP). Indeed, neurological disability is one of the most feared complications in perinatal medicine and its diagnosis antenatally is one of the greatest challenges in obstetrics. What is more, the cause and effect relationship of neurological disabilities, is often uncertain. The assessment of the integrity of the fetal nervous system is a major task in modern perinatal medicine. ${ }^{6,7}$ A ssessment of fetal behavior is time consuming, but only when normal behavior is well understood and documented, will be possible to compare it with abnormal cases, detect the differences between them, and as a result identify and perceive abnormal behavior before birth.

\section{ULTRASOUND FOR THE ASSESSMENT OF FETAL BEHAVIOR}

It has been well established that fetal behavioral patterns are directly related to the degree of development and maturation of the fetal nervous system, ${ }^{8,9}$ while studies have shown, that the quality and quantity of fetal movements are very good indicators of neurobehavioral organization and as a result of the future neurological integrity of the fetus. ${ }^{10-17}$ Two-dimensional (2D) ultrasound allowed the assessment of fetal anatomy and direct monitoring of fetal activity. Precht et al about 30 years ago were the first to study specific fetal movements with 2D ultrasound, performing the first steps in the area of fetal neurosonography, and preparing at the same time the ground for the study of fetal behavior in utero. ${ }^{18}$ De V ries et al analyzed the qualitative and 
Table 1: Major events in neural development

\begin{tabular}{ll}
\hline Developmental event & Peak time of occurrence \\
\hline - Primary neurulation (dorsal induction) & $3-4$ weeks antenatally \\
- Prosencephalic cleavage (ventral induction) & $5-6$ weeks antenatally \\
- Neuronal proliferation & \\
$\quad$ Cerebral & $2-4$ months antenatally \\
$\quad$ Cerebellar & $2-10$ months postnatally \\
- Neuronal migration & \\
$\quad$ Cerebral & $3-5$ months antenatally \\
$\quad$ Cerebellar & $4-10$ months antenatally \\
- Neuronal differentiation & \\
$\quad$ Axon outgrowth & 3 months - birth \\
$\quad$ Dendritic growth and synapse formation & 6 months - 1 year postnatally \\
- Synaptic rearrangement & Birth-years postnatally \\
Myelination & Birth-years postnatally \\
\hline
\end{tabular}

By Kurjak et al. Ultrasound Rev Obstet Gynecol 2004

quantitative aspects of fetal movements and reported not only how to describe a particular movement, but also how these movements were performed in terms of speed and amplitude and participating body movements. ${ }^{19-21}$ It has been suggested that assessment of fetal behavior during different periods of gestation could make it possible to distinguish between normal and abnormal brain development. ${ }^{21-24}$

Since then technology has made huge progress and has offered many options for fetal surveillance, while the development of new ultrasound techniques has allowed direct visualization of the fetus in utero. ${ }^{25-27} \mathrm{H}$ ow ever, 2D ultrasound with poor quality images was considered to be somewhat subjective, because the information needed observer's interpretation. ${ }^{24}$ The overcoming of these problems was made possible with the introduction of 3D/ 4D ultrasound technology, which has been imported in everyday practice and is an important part of routine ultrasound assessment of the fetus. In contrast to 2D ultrasound, 3D visualization of the fetus provides better pictures and real time images that help not only to visualize the fetal anatomy in a much better way than 2D ultrasound, but also to evaluate the movements and the behavior of the fetus in utero. ${ }^{28}$ Studies have shown that 4D ultrasound offers a practical mean of assessment of both brain anatomy and function, with more details and at a much earlier gestational age than $2 \mathrm{D}$ ultrasound does. ${ }^{29}$ It has been proven that $4 \mathrm{D}$ sonography can assist in the better understanding of both the somatic and motor development of the fetus and has led to very important conclusions concerning fetal behavior by enabling us to produce measurable parameters for the assessment of normal neurobehavioral development. ${ }^{30} \mathrm{~W}$ hat is more, $4 \mathrm{D}$ ultrasound, by obtaining real time images, allows spatial observations of fetal face (e.g. smiling, crying, mouthing and blinking), something that cannot be achieved with 2D ultrasound, and multicenter studies have verified that with the use of $4 D$ ultrasound it is feasible to distinguish between normal and abnormal behavioral patterns of the fetus, which could eventually lead to early diagnosis of brain impairment. ${ }^{31,32}$ The advantages of 3D and 4D ultrasound for the assessment of fetal anatomy and fetal behavior, has been shown by large studies. ${ }^{55}$

It is known that fetal movements occur much earlier than the time that mothers can feel them, even during the embryonic period. ${ }^{26}$ The pattern, the quantity and the quality of fetal movements are growing rapidly throughout pregnancy, starting with gross, asynchronized movements of the whole embryo and leading to organized and detailed movements, as well as facial expressions toward the end of the pregnancy. ${ }^{33}$ Studies regarding neonatal neurology have shown that the assessment of neonatal behavior is a better predictor of neurodevelopmental disability than neurological examination. These findings initiated a series of studies that aimed to find the relationship of fetal behavior and developmental processes during specific periods of gestational age, in order to make possible the distinction between normal and abnormal brain development, and also to enable early diagnosis of various structural or functional abnormalities of the fetal nervous system. ${ }^{1-4,18-23,57} \mathrm{~A}$ bout 5 years ago the Zagreb group developed a structured and systematic way for assessing the integrity of the fetal central nervous system, by using $4 \mathrm{D}$ ultrasound. ${ }^{34}$ This new test was called K urjak's antenatal neurodevelopment test (KANET), and its innovation is that it assesses the fetus in utero in the same way that neonates are examined postnatal ly for brain damage, incorporating parameters from neonatal neurological tests (A miel-Tison), with the use of 4D ultrasound. ${ }^{35-37}$

\section{KURJAK ANTENATAL NEURODEVELOPMENTAL TEST (KANET)}

Timely diagnosis of brain impairment is the main reason why so many studies have been conducted regarding the 
anatomical and functional integrity of the fetal nervous system and the understanding of fetal behavior. Based on the results of these studies, scientists have eventually been led to the development of methods for the assessment of fetal and neonatal behavior. ${ }^{1}$ KANET is a new scoring system for the assessment of fetal neurobehavior that was developed by the Zagreb group. This test has been recently introduced and is based on prenatal evaluation of the fetus by $3 \mathrm{D} / 4 \mathrm{D}$ ultrasound. ${ }^{34}$ This scoring system is a combination of some parameters consisting of fetal general movements (GMs) and of postnatal Amiel-Tison Neurological A ssessment at Term (A TNAT) signs, which can be easily visualized prenatally by using $4 \mathrm{D}$ ultrasound. ${ }^{35,39}$ The following parameters have been incorporated in the KA NET test: isolated head anteflexion, overlapping cranial sutures, head circumference, isolated eye blinking, facial al terations, mouth opening (yawning or mouthing), isolated hand and leg movements and thumb position, Gestalt perception of GM s (overall perception of the body and limb movements with their qualitative assessment).

Several papers have shown that there is a continuity of behavior from pre- to postnatal life and it has been observed that all movements that are present at neonates are also present in fetal life, with the exception of Moro's reflex, which cannot be demonstrated in fetuses. ${ }^{40}$ This is probably due to a different environment to which fetus and neonate are exposed. The fetus lives in an environment of microgravity, while the newborn is exposed to full gravity, which creates certain obstacles for neurodevelopment in the first months of life. ${ }^{6}$ The parameters were chosen based on developmental approach to the neurological assessment and on the theory of central pattern generators of GM S emergence, and were the product of multicentric studies conducted for several years. ${ }^{38,39} \mathrm{KANET}$ is a combination of assessments of fetal behavior, GM $s$ and three out of four signs which have been postnatally considered as symptoms of possible neurodevelopmental impairment (neurological thumb, overlapping sutures and small head circumference). ${ }^{41}$

KANET test was standardized in Osaka, Japan on the 24th of October 2010, in order for the test to become reproducible and easily applied by fetal medicine specialists. ${ }^{41} \mathrm{~A}$ ccording to the 0 saka Consensus Statement the KANET should be performed in the 3rd trimester of pregnancy, between 28 and 38 weeks. The duration of the examination should be between 15 and 20 minutes, and fetuses should be examined while they are awake. If the fetus is in the sleeping period, the assessment should be postponed for 30 minutes or for the following day, at a minimum period of 14 to 16 hours. In cases of grossly
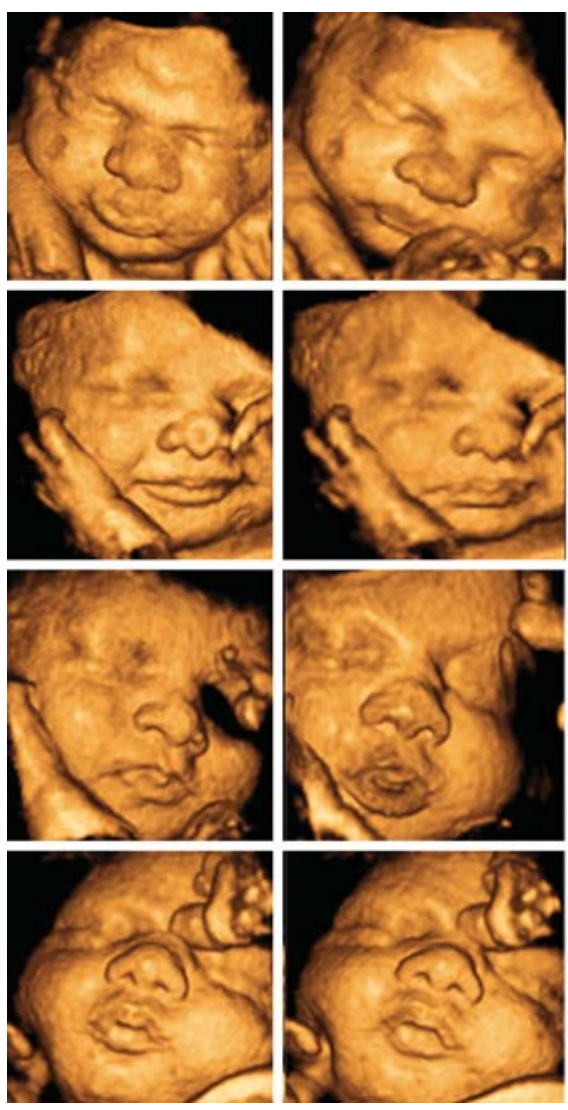

Fig. 1: Normal KANET score at 34 weeks of pregnancy
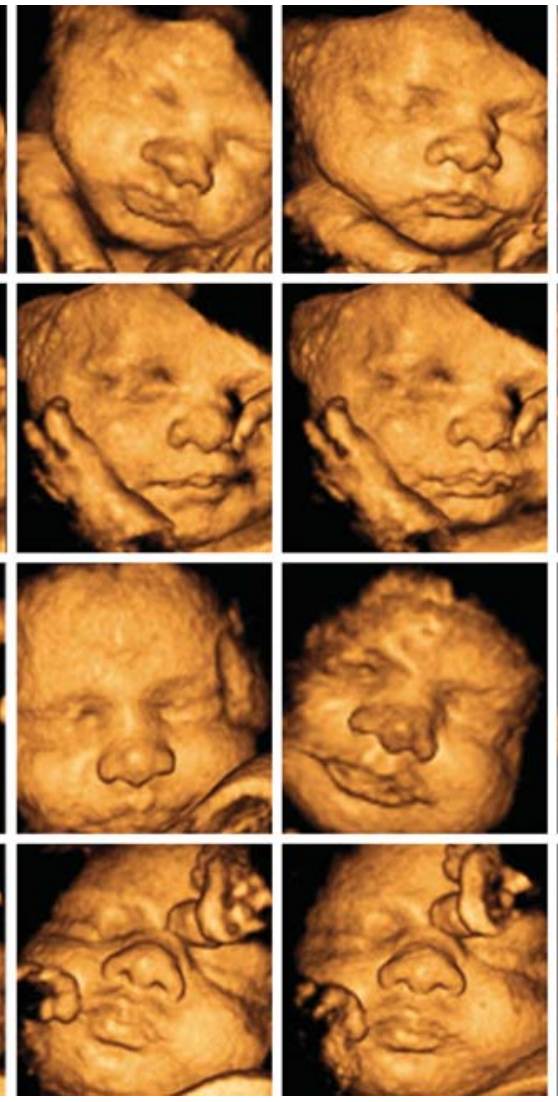
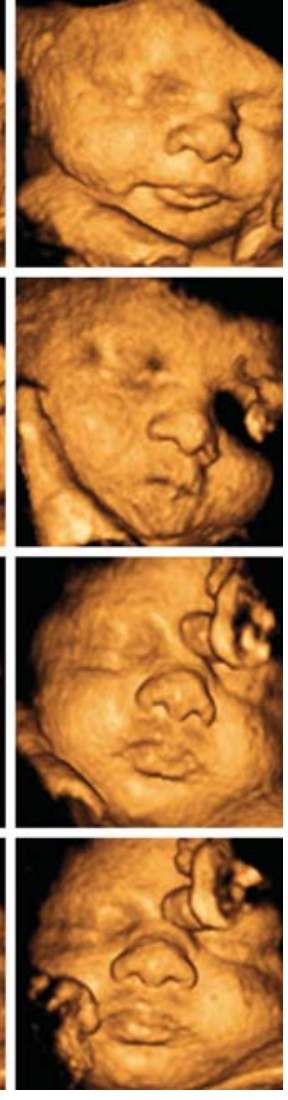

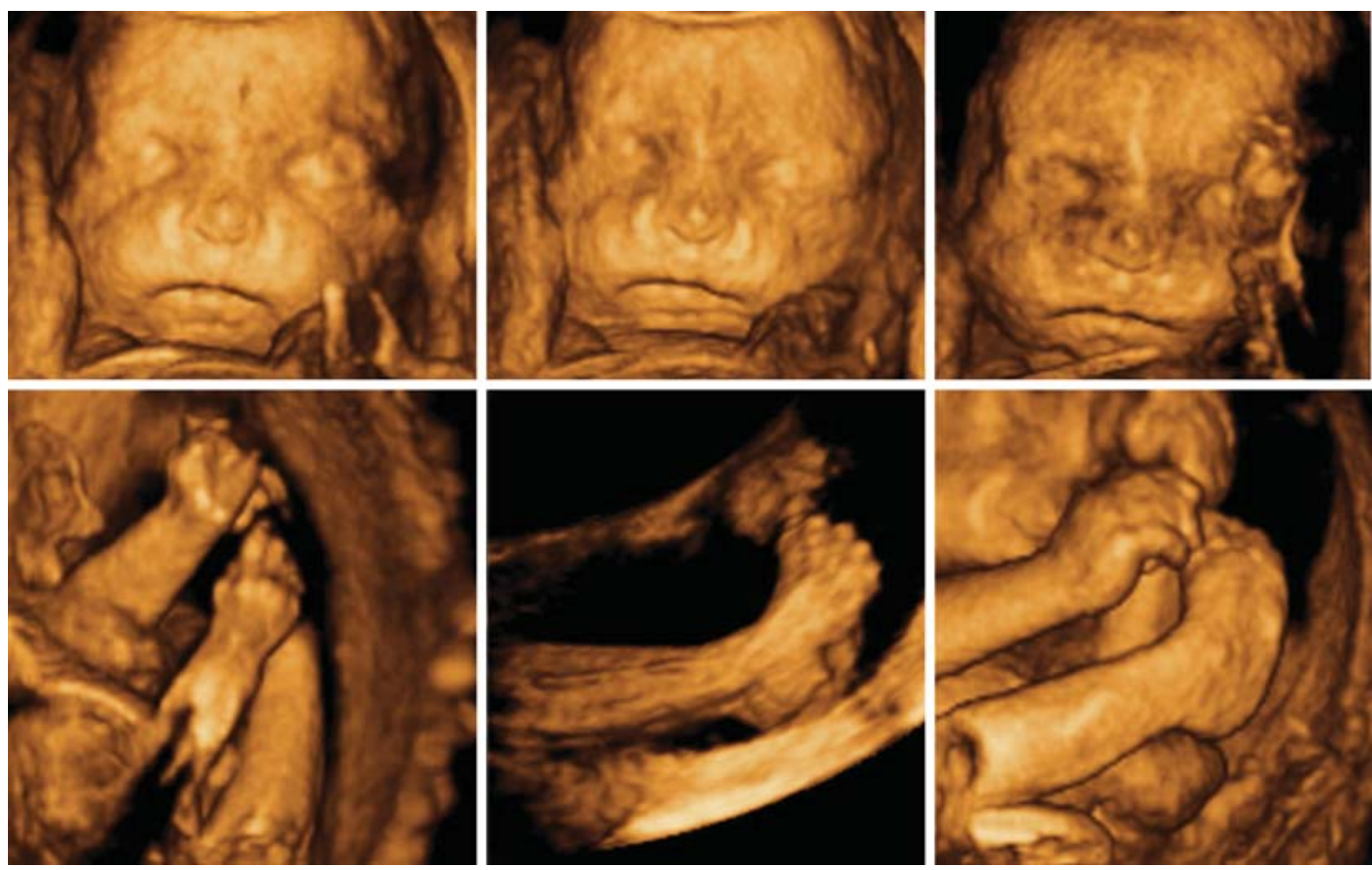

Fig. 2A: Abnormal KANET score at 28 weeks of a fetus with severe hydranencephaly after CMV infection. No facial alterations or mouth movements were identified ('frozen face or face like mask'), fists remained clenched and no leg movements were seen (right foot deviated inward-club foot)
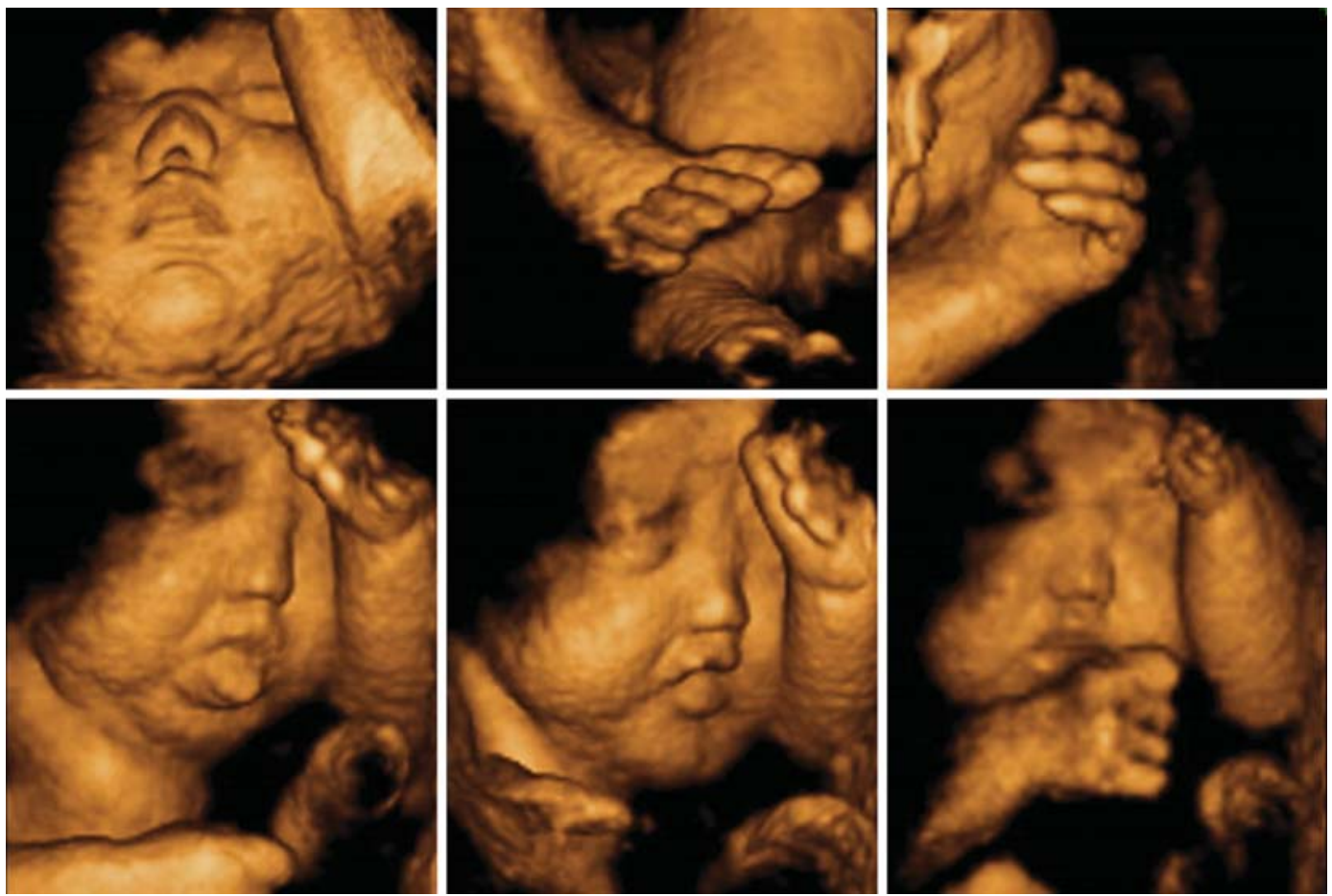

Fig. 2B: Abnormal KANET score at 31 weeks of gestation, of a fetus with semilobar holoprosencephaly. Mouth movements were identified (tongue expulsion), but otherwise facial alterations were minimal and the KANET score was abnormal (KANET score $=4)$. No leg movements were seen and neurological thumb was identified. Neonate died 3 days after delivery

abnormal or of borderline score, the test should be repeated every 2 weeks until delivery. Special attention should be paid to the facial movements and to eye blinking, which are prenatally very informative and important ('the face is the mirror of the brain'). The frequency of facial and mouth movements should be 0 to 5 and more than 5 . Overall number of movements should be defined in very active or inactive fetuses and compared with normal values of previous studies. ${ }^{38,39}$ (Figs 1 and 2). All the examiners should have extensive hands-on education for the application of KANET test, both in low and in high-risk pregnancies. Interobserver and intraobserver variability 
Functional Test for Fetal Brain: The Role of KANET Test

Table 2: Proposal for the new KANET assessment tool consisting of eight parameters

\begin{tabular}{llll}
\hline Sign & & Score & Sign score \\
\cline { 2 - 3 } & 0 & 1 & 2 \\
\hline Isolated head anteflexion & Abrupt & $\begin{array}{l}\text { Small range } \\
(0-3 \text { times of } \\
\text { movements) }\end{array}$ & $\begin{array}{l}\text { Variable in full range, } \\
\text { many alteration (>3 } \\
\text { times of movements) }\end{array}$
\end{tabular}

Cranial sutures and head circumference
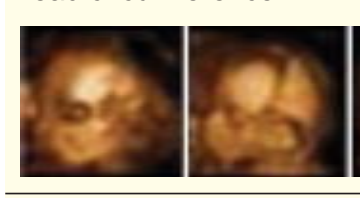

Isolated eye blinking

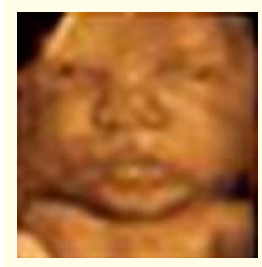

Facial alteration (grimace

or tongue expulsion)

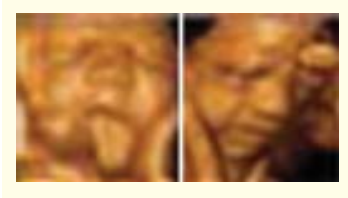

or

mouth opening

(yawning or mouthing)

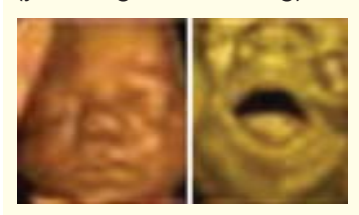

Isolated leg movement

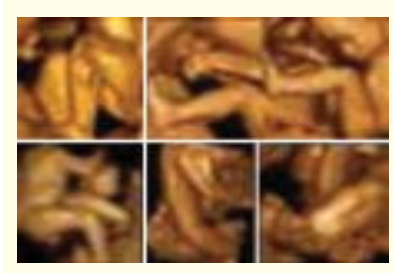

Cramped

Overlapping of cranial sutures

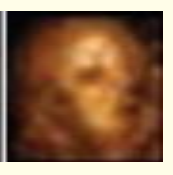

Not present

Not present Not fluent (1-5 times of
alteration)

Fluency ( $>5$ times of alteration)
Normal cranial sutures

Normal cranial sutures

below the normal limit

(-2 SD) according to GA

of $\mathrm{HC}$ according to $\mathrm{GA}$
Not fluent (1-5 times of blinking)

Fluency ( $>5$ times of blinking)
Poor repertoire or

small in range

(0-5 times of movement)
Variable in full range, many alternation ( $>5$ times of movement)

Isolated hand movement

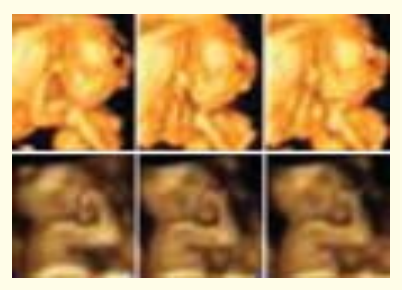

Contd... 


\begin{tabular}{|c|c|c|c|}
\hline \multirow[t]{2}{*}{ Sign } & \multicolumn{3}{|c|}{ Score } \\
\hline & 0 & 1 & 2 \\
\hline or hand to face movements & Cramped or abrupt & $\begin{array}{l}\text { Poor repertoire or } \\
\text { small in range (0-5 } \\
\text { times of movement) }\end{array}$ & $\begin{array}{l}\text { Variable in full range, } \\
\text { many alternation ( }>5 \\
\text { times of movements) }\end{array}$ \\
\hline Fingers movements & $\begin{array}{l}\text { Unilateral or bilateral } \\
\text { clenched fist, } \\
\text { (neurological thumb) }\end{array}$ & $\begin{array}{l}\text { Cramped invariable } \\
\text { finger movements }\end{array}$ & $\begin{array}{l}\text { S mooth and complex, } \\
\text { variable finger } \\
\text { movements }\end{array}$ \\
\hline \multirow[t]{2}{*}{ Gestalt perception of GMs } & Definitely abnormal & Borderline & Normal \\
\hline & & & Total score \\
\hline
\end{tabular}

Stanojevic et al. Osaka Consensus Statement. DSJ UOG 2011;5(4):317-329.

should be available. It is advisable to use 4D ultrasound machines, with frame rate of minimum 24 volumes/second. The O saka Consensus Statement concluded that the K A NET should use eight parameters rather than 10, for the assessment of the fetus (Table 2). A score range of 0 to 5 is characterized as abnormal, a score calculated from 6 to 13 is considered borderline and a score range of 14 to 20 is normal (Table 3). After that neonates should be followed up postnatally for neurological development for a 2 years period.

The test evaluates quantitative as well as qualitative aspects of fetal motor behavioral patterns. This technique supplies more convincing images/video sequences than conventional ultrasonic and nonultrasonic methods, enabling to observe fetal movements in their full repertoire and variability. The parameters examined by this test are partly based on observation of GMs. A second group of parameters is adopted from ATNAT. ${ }^{42,43}$ The criterion of quality and quantity of spontaneous GM s is believed to have excellent reliability in evaluating the integrity of fetal CN S. ${ }^{22,44}$ Furthermore, a continuity of behavioral patterns from prenatal to the postnatal period has been proven. ${ }^{45-47}$ This continuity allows the ultrasonography to derive a fetal assessment from newborn neurologic findings. B oth those facts justify the choice of the parameters used in this test, making K A NET theoretically appropriate for the assessment of fetal behavior. A ccording to previous reports ${ }^{48-53}$ K A NET easily recognizes serious functional impairment associated with structural abnormalities. Recent studies have shown that the application of KANET in both low and high risk populations has given very promising results about the
Table 3: Interpretation of KANET scores

\begin{tabular}{ll}
\hline Total score & Interpretation \\
\hline $0-5$ & Abnormal \\
$6-9$ & Borderline \\
$10-16$ & Normal \\
\hline
\end{tabular}

Stanojevic et al. Osaka Consensus Statement. DSJUOG 2011;5(4):317-329.

outcome of the fetuses and especially in high risk populations, the result of KANET may provide extremely useful information and guidelines for the counseling of the neurological outcome of these fetuses. ${ }^{54}$ The KANET is the first test which is based on $4 D$ ultrasound, with an original scoring system and has been standardized, so it can be implemented in everyday practice, overcoming the practical difficulties and covering the gaps of methods that were used in the past for the evaluation of fetal behavior. ${ }^{56-59} \mathrm{M}$ ore recent studies show evidence that KANET is easily applicable to the majority of pregnancies, the learning curve is short for physicians who already have training in obstetrical ultrasound and the actual time of the KANET is very reasonable, ranging from 15 to 20 minutes, showing strong evidence that it can be widely implemented for fetal neurological assessment. ${ }^{52} \mathrm{As}$ a conclusion, the results of recent, large multicenter studies show that KA NET is an easily applied, standardized test, which utilizes the advantages of $4 \mathrm{D}$ ultrasound, such as better analysis of facial expressions and quality (variability and complexity) of fetal movements, in order to distinguish between normal and abnormal behavioral patterns of the fetus, with the aim of early recognition of fetal brain impairment. ${ }^{41}$ 


\section{EVIDENCES OF PRENATAL DETECTION BY MULTICENTRIC STUDIES}

One of the first studies to use a preliminary form of the KANET scoring system was that by Andonotopo et al in 2006. They aimed to assess fetal facial expression and quality of body movements and examine if they are of diagnostic value for brain impairment in fetuses with growth restriction. In that prospective study of 50 pregnancies with intrauterine growth restriction (IUGR) fetuses in the 3rd trimester of pregnancy, a tendency of less behavioral activity in IU GR than normal fetuses has been noted. The results of the study encouraged future investigation of the use of $4 D$ ultrasound for quantitative and qualitative assessment of fetal behavior as possible indicators of the neurological condition in IUGR fetuses. ${ }^{53}$

The Zagreb group in 2008, were the first to introduce the KANET for the assessment of neurological status of the fetus, aiming to the detection of fetal brain and neurodevelopmental alterations due to in utero brain impairment. In order to develop the new scoring system they identified severely brain damaged neonates and neonates with good neurological condition and then compared the neonatal findings, with corresponding findings in utero. In the group of 100 low-risk pregnancies they retrospectively applied KANET. A fter delivery, postnatal neurological assessment (ATNAT) was performed and all neonates assessed as normal reached a score between 14 and 20, which was assumed to be the score of optimal neurological development. N ew scoring system was applied in the group of 120 high-risk pregnancies in which, based on postnatal neurological findings, three subgroups of newborns were identified: normal, mildly or moderately abnormal and abnormal. Based on this, a neurological scoring system has been proposed. All normal fetuses reached a score from 14 to 20 . Ten fetuses who were postnatally described as mildly or moderately abnormal achieved a prenatal score of 5 to 13 , while another 10 fetuses postnatally assigned as neurologically abnormal had a prenatal score 0 to 5 . A mong this group four had alobar holoprosencephaly, one had severe hypertensive hydrocephaly, one had thanatophoric dysplasia and four fetuses had multiple malformations. This study inspired a large series of multicenter studies (Table 4) that used the KA NET in order to assess the usefulness of this promising new scoring system for the assessment of neurological status in fetuses and the recognition of signs of early brain impairment in utero. ${ }^{25,32}$

The results of the first multicenter study, which included 288 high-risk pregnancies, from four different centers, were published in 2010. They identified seven cases with abnormal KANET and 25 cases with borderline KANET score, yielding 32 fetuses at neurological risk. There were also 11 cases with abnormal KANET, of which six fetuses died in uteroand five were terminated. The seven remaining neonates with abnormal KANET were followed up postnatally at 10 weeks and out of these seven cases, three were found to have abnormal A TN A T scoring postnatally. These w ere a case of arthrogryposis, a case of vermis aplasia and a fetus whose previous sibling had verified CP. The fetuses in these three cases had especially reduced facial movements-the faces were like masks during the ultrasounds. The remaining four cases were considered normal (ventriculomegaly, pre-eclampsia, thrombophilia, oligohydramnios). Out of 25 borderline K A NET there were 22 borderline newborns by ATNAT, whereas three were normal (ventriculomegaly, syndrome of intra-amniotic infection, maternal thrombocytopenia). Those who were abnormal prenatally and normal postnatally had the following prenatal risk-factors: ventriculomegaly, DandyWalker malformation, skeletal dysplasia, polyhydramnios, gestational diabetes, hydrocephaly, thrombophilia, preeclampsia, achondroplasia, oligohydramnios, nonimmune hydrops, intra-amniotic infection, IU GR, trisomy 21 , thrombocytopenia. Out of three abnormal neonates after ATNAT assessment two had definitely abnormal Prechtl's premature GM s (arthrogryposis and vermis aplasia) and an additional six were considered abnormal (neonate of the mother with the previous child with $C P$, Dandy-Walker syndrome, hydrocephaly, trisomy 21 , ventriculomegaly, nonimmune hydrops). The remaining 21 children had normal optimal or normal suboptimal GMs. During their study they also followed the pregnancy of a fetus with acrania, which the mother had refused to terminate due to religious reasons, documenting the evolution of the fetal behavior from 20 weeks and as the motor control was shifting from the lower to the upper control center the fetus ended up with a very low KANET score. The authors reached the conclusion that there is a potential for antenatal detection of serious neurological conditions, especially in identifying the fetuses from high-risk pregnancies at neurological risk. ${ }^{48}$

M iskovic et al applied K A NET in 226 cases, both highand low-risk pregnancies and compared the results. They found three cases of abnormal KANET, that had chromosomal abnormalities and all three had abnormal ATNAT, as well. The KANET scores from both groups were compared to the results of the ATNAT tests, and found statistically significant difference among the low and the high risk groups, for eight out of the $10 \mathrm{~K}$ A NET parameters (isolated anteflexion of the head, eye blinking, facial expressions-grimacing, tongue expulsion, mouth movement 


\begin{tabular}{|c|c|c|c|c|c|c|c|c|c|c|}
\hline Author & Year & Study & $\begin{array}{l}\text { Study } \\
\text { design }\end{array}$ & $\begin{array}{l}\text { Study } \\
\text { population }\end{array}$ & Indication & No & $\begin{array}{l}\text { GA } \\
\text { (weeks) }\end{array}$ & $\begin{array}{l}\text { Time } \\
\text { (mins) }\end{array}$ & Result & Summary \\
\hline Kurjak et al ${ }^{15}$ & 2008 & Cohort & Retrospective & High-risk & Multiple & 220 & $20-36$ & 30 & Positive & $\begin{array}{l}\text { A new scoring system } \\
\text { was proposed for the } \\
\text { antenatal assessment } \\
\text { of fetal neurological } \\
\text { status }\end{array}$ \\
\hline Kurjak et $\mathrm{al}^{28}$ & 2010 & Multicenter & Prospective & High-risk & Multiple & 288 & $20-38$ & 30 & Positive & $\begin{array}{l}\text { KANET appeared to } \\
\text { be prognostic of } \\
\text { antenatal detection of } \\
\text { serious neurological } \\
\text { fetal problems. } \\
\text { KANET also identified } \\
\text { fetuses with severe } \\
\text { structural abnormalities, } \\
\text { especially associated } \\
\text { with brain impairment }\end{array}$ \\
\hline Miskovic et al ${ }^{32}$ & 2010 & Cohort & Prospective & High-risk & Multiple & 226 & $20-36$ & 30 & Positive & $\begin{array}{l}\text { Correlation between } \\
\text { antenatal (KANET) } \\
\text { and postnatal } \\
\text { (ATNAT) results was } \\
\text { found. KANET showed } \\
\text { differences of fetal } \\
\text { behavior between } \\
\text { high- and low-risk } \\
\text { pregnancies }\end{array}$ \\
\hline Talic et al ${ }^{31}$ & 2011 & $\begin{array}{l}\text { Multicenter } \\
\text { Cohort }\end{array}$ & Prospective & High-risk & Multiple & 620 & $26-38$ & $15-20$ & Positive & $\begin{array}{l}\text { KANET test had a } \\
\text { prognostic value in } \\
\text { discriminating normal } \\
\text { from borderline and } \\
\text { abnormal fetal } \\
\text { behavior, in normal } \\
\text { and in high risk cases. } \\
\text { Abnormal KANET } \\
\text { scores were } \\
\text { predictable of both } \\
\text { intrauterine and } \\
\text { postnatal death }\end{array}$ \\
\hline Talic et al ${ }^{29}$ & 2011 & $\begin{array}{l}\text { Multicenter } \\
\text { Cohort }\end{array}$ & Prospective & High-risk & $\begin{array}{l}\text { Ventriculo- } \\
\text { megali }\end{array}$ & 240 & $32-36$ & $10-15$ & Positive & $\begin{array}{l}\text { Statistically significant } \\
\text { difference was } \\
\text { identified in KANET } \\
\text { scores between } \\
\text { normal pregnancies } \\
\text { and pregnancies with } \\
\text { ventriculomegaly. } \\
\text { Abnormal KANET } \\
\text { scores and most of the } \\
\text { borderline scores were } \\
\text { noted in fetuses with } \\
\text { severe ventriculomegaly, } \\
\text { especially associated } \\
\text { with additional } \\
\text { abnormalities }\end{array}$ \\
\hline $\begin{array}{l}\text { Honemeyer } \\
\text { et al }{ }^{39}\end{array}$ & 2011 & Cohort & Prospective & Unselected & Unselected & 100 & $28-38$ & $\mathrm{~N} / \mathrm{A}$ & Positive & $\begin{array}{l}\text { Normal prenatal } \\
\text { KANET scores had a } \\
\text { significant predictive } \\
\text { value of a normal } \\
\text { postnatal neurological } \\
\text { evaluation }\end{array}$ \\
\hline Lebit et al $^{14}$ & 2011 & Cohort & Prospective & Low-risk & $\begin{array}{l}\text { Normal 2D } \\
\text { examination }\end{array}$ & 144 & $7-38$ & $15-20$ & Positive & $\begin{array}{l}\text { A specific pattern of } \\
\text { fetal neurobehavior } \\
\text { corresponding to each } \\
\text { trimester of pregnancy } \\
\text { was identified }\end{array}$ \\
\hline
\end{tabular}

Contd... 
Functional Test for Fetal Brain: The Role of KANET Test

Contd...

\begin{tabular}{|c|c|c|c|c|c|c|c|c|c|c|}
\hline Author & Year & Study & $\begin{array}{l}\text { Study } \\
\text { design }\end{array}$ & $\begin{array}{l}\text { Study } \\
\text { population }\end{array}$ & Indication & No & $\begin{array}{l}\text { GA } \\
\text { (weeks) }\end{array}$ & $\begin{array}{l}\text { Time } \\
\text { (mins) }\end{array}$ & Result & Summary \\
\hline $\begin{array}{l}\text { Abo-Yaqoub } \\
\text { et al }\left.\right|^{50}\end{array}$ & 2012 & Cohort & Prospective & High-risk & Multiple & 80 & $20-38$ & $15-20$ & Positive & $\begin{array}{l}\text { Significant difference } \\
\text { in KANET scores was } \\
\text { noted. All antenatally } \\
\text { abnormal KANET } \\
\text { scores had also an } \\
\text { abnormal postnatal } \\
\text { neurological } \\
\text { assessment }\end{array}$ \\
\hline 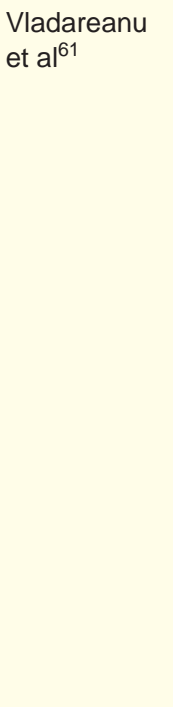 & 2012 & Cohort & Prospective & High-risk & Multiple & 196 & $24-38$ & N/A & Positive & $\begin{array}{l}\text { Most fetuses with } \\
\text { normal KANET } \rightarrow \text { low- } \\
\text { risk, those with } \\
\text { borderline } \rightarrow \text { IUGR } \\
\text { fetuses with increased } \\
\text { MCA RI and most } \\
\text { fetuses with abnormal } \\
\text { KANET } \rightarrow \text { threatened } \\
\text { PTD with PPROM. } \\
\text { Difference in fetal } \\
\text { movements was } \\
\text { identified between the } \\
\text { two groups. For } \\
\text { normal pregnancies } \rightarrow \\
\text { 93.4\% of fetuses } \\
\text { achieved normal } \\
\text { score, for high-risk } \\
\text { pregnancies } \rightarrow 78.5 \% \\
\text { of fetuses had a } \\
\text { normal score }\end{array}$ \\
\hline $\begin{array}{l}\text { Honemeyer } \\
\text { et al }{ }^{62}\end{array}$ & 2012 & Cohort & Prospective & $\begin{array}{l}\text { High- and } \\
\text { low-risk }\end{array}$ & Multiple & 56 & $28-38$ & $\begin{array}{l}30 \\
\max \end{array}$ & Positive & $\begin{array}{l}\text { Introduction of the } \\
\text { average KANET } \\
\text { score } \rightarrow \text { combination of } \\
\text { the mean value of } \\
\text { KANET scores } \\
\text { throughout pregnancy } \\
\text { Revealed a } \\
\text { relationship of fetal } \\
\text { diurnal rhythm with the } \\
\text { pregnancy risk }\end{array}$ \\
\hline Kurjak et al ${ }^{73}$ & 2013 & Cohort & Prospective & $\begin{array}{l}\text { High- and } \\
\text { low-risk }\end{array}$ & Multiple & 869 & $28-38$ & 20 & Positive & $\begin{array}{l}\text { Statistically significant } \\
\text { differences in the } \\
\text { distribution of normal, } \\
\text { abnormal, and } \\
\text { borderline KANET } \\
\text { scores between low- } \\
\text { risk and high-risk } \\
\text { groups were found. } \\
\text { Fetal behavior was } \\
\text { significantly different } \\
\text { between the normal } \\
\text { group and the } \\
\text { high-risk subgroups }\end{array}$ \\
\hline \multirow[t]{2}{*}{$\begin{array}{l}\text { Predojevic } \\
\text { et } \mathrm{al}^{75}\end{array}$} & 2013 & Case study & Prospective & High-risk & IUGR & 5 & $31-39$ & 30 & Positive & $\begin{array}{l}\text { KANET could } \\
\text { recognize pathologic } \\
\text { and borderline } \\
\text { behavior in IUGR } \\
\text { fetuses with or without } \\
\text { blood flow redistribution. } \\
\text { Combined } \\
\text { assessment of } \\
\text { hemodynamic and } \\
\text { motoric parameters } \\
\text { could enable in better } \\
\text { diagnosis and } \\
\text { consultation }\end{array}$ \\
\hline & & & & & & & & & & Contd... \\
\hline
\end{tabular}




\begin{tabular}{|c|c|c|c|c|c|c|c|c|c|c|}
\hline Author & Year & Study & $\begin{array}{l}\text { Study } \\
\text { design }\end{array}$ & $\begin{array}{l}\text { Study } \\
\text { population }\end{array}$ & Indication & No & $\begin{array}{l}\text { GA } \\
\text { (weeks) }\end{array}$ & $\begin{array}{l}\text { Time } \\
\text { (mins) }\end{array}$ & Result & Summary \\
\hline $\begin{array}{l}\text { Athanasiadis } \\
\text { et } \mathrm{al}^{74}\end{array}$ & 2013 & Cohort & Prospective & $\begin{array}{l}\text { Unselected } \\
\text { (High- and } \\
\text { low-risk) }\end{array}$ & $\begin{array}{l}\text { Multiple } \\
\text { (IUGR, PET, } \\
\text { GDM) }\end{array}$ & 152 & $\begin{array}{l}\text { 2nd and } \\
\text { 3rd } \\
\text { trimester }\end{array}$ & $\mathrm{N} / \mathrm{A}$ & Positive & $\begin{array}{l}\text { The neurodevelop- } \\
\text { mental score was } \\
\text { statistically significant } \\
\text { higher in the low-risk } \\
\text { group compared to the } \\
\text { high-risk group ( } p< \\
0.0004 \text { ). The diabetes } \\
\text { subgroup score was } \\
\text { statistically } \\
\text { significantly higher } \\
\text { compared to the IUGR } \\
\text { and the pre-eclampsia } \\
\text { subgroup ( } p=0.0001 \text { ). }\end{array}$ \\
\hline
\end{tabular}

KANET: Kurjak's antenatal neurological test; No: number of patients; IUGR: intrauterine growth restriction; MCA: middle cerebral artery; PTD: preterm delivery; PPROM: preterm premature rupture of membranes; PET: pre-eclampsia; GDM: gestational diabetes mellitus

such as yawning, jawing, swallowing-isolated hand movements, hand to face movements, fist and finger movements and GM s). Comparison of KANET and ATNAT showed statistically significant, moderate correlation between the two tests, which means that the neuropediatric exam (ATNAT) confirmed the prenatal findings of $4 \mathrm{D}$ ultrasound examination (KANET). The authors concluded that these preliminary results were promising and stated that further studies are needed before the test could be recommended for wider clinical practice. ${ }^{52}$

Talic et al around the same period, in a multicenter study, published the largest series of KANET so far, with 620 singleton pregnancies, both low and high risk cases (100 low risk and 520 high risk cases), excluding however fetuses with structural abnormalities, that were studied between 26 and 38 weeks of gestation. Fetuses with congenital anomalies multiple pregnancies were excluded from the study. The high risk group of patients consisted of the following subgroups: threatened preterm delivery with or without preterm rupture of membranes (PPROM ), previous child diagnosed with $C P$, hypertension in pregnancy with or without pre-eclampsia, diabetes before pregnancy or gestational diabetes, intrauterine growth restriction, polyhydramnios, Rhesus isoimmunization, placental bleeding and maternal fever $>39^{\circ} \mathrm{C}$. A nalysis of the data confirmed statistically significant difference in the distribution of fetal KANET scores between the two populations. Impressively the largest incidence of fetuses with abnormal KANET was noticed in the subgroup of participants with a previous child diagnosed with $C P$ (23.8\%) and the largest incidence of fetuses with borderline KANET was observed in the subgroup of mothers with fever $(56.4 \%)$. The following parameters of KANET test significantly differed between the fetuses from low- and high-risk pregnancies: overlapping cranial sutures, head circumference, isolated eye blinking, facial expressions, mouth movements, isolated hand movements, isolated leg movements, hand to face movements, finger movements and GM s. The authors observed that a low K ANET score is predictive of both intrauterine or neonatal death-they had two intrauterine deaths in fetuses with low KA NET (scores of 3 and 4 respectively) and one neonatal death (with a KANET score of 2). In 10 out of 36 fetuses with abnormal KANET after 2 and 6 months, postnatal neurological examination indicated severely abnormal finding: four of them had severe generalized spasticity. The study demonstrated the potential of KANET to detect and discriminate normal from borderline and abnormal fetal behavior in normal and in high-risk pregnancies. Other neonates are still followed up in this study, in order to reach safe conclusions. ${ }^{51}$

Honemeyer et al studied 100 fetuses, who underwent, between 28 and 38 weeks of gestation, up to three times during their pregnancy assessment by KANET. The fetuses were followed-up postnatally, immediately after delivery and again at 12 weeks of life, with systematic neurological assessment by the neonatologist. The results from the scoring systems of pre- and postnatal evaluation were compared. Results showed that a normal prenatal KANET score is significantly predictive of normal postnatal neurological assessment of the new born immediately after delivery and at 12 weeks of life. The authors concluded that that normal antenatal KANET scores is a very good predictor of a normal postnatal neurological outcome. ${ }^{60}$

Lebit et al used part of the KANET to assess fetal movements throughout pregnancy in 144 low-risk pregnancies, between 7 and 38 weeks of gestation, concluding to a specific pattern of fetal behavior for each trimester of pregnancy. ${ }^{33}$ The authors noticed that in the first trimester fetal movements grow rapidly in frequency 
Functional Test for Fetal Brain: The Role of KANET Test

and complexity, while in the second half of pregnancy the motor behavior significantly increases in frequency and variability. Facial expressions and eye movements also appear in second trimester, with the first eye movements starting at about 18 weeks. In late pregnancy fetal movements show a decline and the periods of rest start to grow. This decrease is rather a consequence of the brain maturation process rather than reduced amount of amniotic fluid. ${ }^{25,26}$ They concluded that dynamic evaluation of fetal behavior reflects directly the processes of maturation and development of the central nervous system and that KA NET test has much to offer in the assessment of fetal behavior. ${ }^{33}$

A very important study was that by Talic et al which aimed to assess the differences in fetal behavior in both normal fetuses and fetuses with cerebral ventriculomegaly, by using KANET. They studied 240 fetuses between 32 and 36 weeks of gestation, 140 fetuses with ventriculomegaly and 100 normal fetuses. Six percent of the fetuses from the low risk-control group had pathological KANET scores, while $34.9 \%$ of the fetuses with ventriculomegaly had pathological K ANET. The largest number of abnormal KANET scores was found in 22 fetuses with severe ventriculomegaly, accompanied by other structural abnormalities ( $D$ andy-Walker, A rnold-Chiari, agenesis of the corpus callosum, holoprosencephaly, encephalocele, spina bifida, choroid plexus cyst, osteogenesis imperfect type II, thanatophoric dysplasia type I and M eckel-Gruber syndrome). There were no fetuses with abnormal KANET in the group of isolated mild and moderate ventriculomegaly. The authors concluded that prenatal neurological findings of the fetuses by application of KANET test is in concordance with their postnatal outcome and that evaluation of fetal behavior by KANET in fetuses with cerebral ventriculomegaly had the potential to detect fetuses with abnormal behavior, adding a functional dimension of the central nervous system evaluation to the brain morphology. Also the degree of ventriculomegaly and the presence of coexisting congenital malformations, appeared to be important factors determining the final KANET score. The results of this study were very positive and showed that KA NET could provide useful information for the correct assessment and counseling of patients with a common finding, such as ventriculomegaly, the significance of which is not well defined. ${ }^{54}$

M ore recently, A bo-Y aqoub et al studied 40 pregnant women with high-risk pregnancies for neurological abnormalities, between 20 and 38 weeks of gestation using KANET scoring system and compared the results with 40 low risk cases, in order to determine the role of $4 D$ ultrasound in prenatal assessment of fetal neurobehavior and in the prediction of adverse neurological outcome. The difference in the range of KANET score was significant between the two groups and all cases with abnormal KANET proved to be abnormal postnatally, whereas those with normal or borderline KANET scores were neurologically normal at least in the early neonatal period that they were assessed. The parameters that were significantly different between the two groups were: isolated head anteflexion, isolated eye blinking, facial expressions, mouth movements, isolated hand movements hand-to-face movements, finger movements and GMs. For isolated leg movements and cranial sutures, the difference was not significant. ${ }^{50}$

V ladareanu et al applied KANET in 196 singleton pregnancies (61 low risk and 135 high-risk patients) between 24 and 38 weeks of gestation in a period of 3 years. M ost fetuses in the study who obtained normal KANET score belonged to the low-risk pregnancies, those who obtained borderline score were fetuses with IU GR and with increased resistance index (RI) of middle cerebral artery (MCA) and most fetuses with abnormal KANET score derived from pregnancies complicated by threatened preterm delivery with PPROM. There was statistical significant difference in fetal movements in the two groups. In normal pregnancies, most fetuses $(93.4 \%)$ achieved a normal KANET score compared to $78.5 \%$ of the fetuses from high-risk pregnancies. B orderline and abnormal scores were dominant in high-risk pregnancies. In the high-risk pregnancy group, most abnormal KANET scores were in pregnancies complicated by threatened preterm delivery with PPROM (25\%). M ost fetuses with pregnancies complicated by IU GR with M CA RI index changes and with hypertension above $160 / 100 \mathrm{~mm} \mathrm{Hg}$ achieved borderline score (50\%). The highest percentage of normal fetal movements was found in pregnancies complicated by $\mathrm{R} h$ isoimmunization without hydrops fetalis ( $96 \%$ ). The characteristics of reduced speed and amplitude were found in the threatened preterm delivery group. There was a reduction of both number and duration of GMs in the IUGR group. The IUGR fetuses moved less and their GM s were poorly organized. A lterations in the quality of fetal movements were accompanied by considerable decrease in the quantity of fetal movements. The authors concluded that K ANET can be useful for early diagnosis of neurological disorders that become manifest in perinatal and postnatal period. ${ }^{61}$

Honemeyer et al studied 56 singleton pregnancies ( 24 low-risk and 32 high-risk cases) between 28 and 38 weeks of gestation and applied serial KANETs on them, performing a total of 117 tests in total. They did not identify any abnormal KANET scores, but two thirds of the borderline scores occurred in the high-risk pregnancies. B ecause they 
performed more than one KANET in each pregnancy they introduced the average KA NET score, which derived from the scores of each fetus during pregnancy. Only one fetus had a borderline average K A NET score, and this fetus who belonged to the high-risk group, was the only one out of 56 pregnancies who had an abnormal early neurological outcome. When the authors compared all the 18 borderline KANET scores with fetal diurnal rhythm based on maternal observation, they noticed that $89 \%$ of the borderline scores of the at-risk group were recorded at times that the mothers characterized them as active periods, compared with 33.3\% in the low-risk pregnancies. The authors concluded that KANET is suggestive of expressing the risk for neurodevelopmental fetal disorders, but the connection of fetal diurnal rhythm and pregnancy risk status should be investigated further. ${ }^{62}$

Kurjak et al studied 869 high- and low-risk singleton pregnancies taking under consideration the results of the Doppler studies of umbilical and middle cerebral arteries, and noticed that fetal behavior was significantly different between the normal group and the following subgroups of fetuses: fetal growth restriction (FGR), gestational diabetes mellitus, threatened preterm birth, antepartum hemorrhage, maternal fever, sibling with $C P$, and polyhydramnios. ${ }^{73} T$ he authors concluded that their study showed a new clinical application of the KANET test in early identification of fetuses at risk for adverse neurological outcome.

\section{FIVE-YEAR VIEW}

KANET appears to be a diagnostic tool of great potential for obstetricians, particularly for the detection of problems that were inaccessible any other method until now by, such as fetal brain impairment and neurodevelopmental alterations. ${ }^{39}$ Of course as a new method, additional studies in large populations are needed before recommending the test in routine clinical practice. So far, studies have shown that KANET is useful for the standardization of neurobehavioral assessment, with the potential of detecting antenatally fetuses with severe neurological impairment, ${ }^{26,46,49}$ and that introduction of KANET in clinical practice at least for the assessment of high-risk pregnancies is feasible. Ongoing studies aim to further investigate the potential of this new method setting the guidelines for a complete fetal neurosonography and neurobehavior assessment. ${ }^{72}$ The continuous knowledge that we gain by studying fetal neurobehavior in a systematic way with the application of a standardized method such as KANET, in combination with the unrelenting technological advantage of $4 \mathrm{D}$ ultrasonography gives the impression that in the near future perinatal medicine will be able to give answers to the everlasting problem of assessing functional development of the fetal nervous system.

\section{EXPERT COMMENTARY}

One of the greatest challenges of obstetrical ultrasonography is the better understanding of fetal neurological function. ${ }^{37,63}$ Neurological problems, such as CP are poorly understood and often falsely attributed to intrapartum events, while for the majority of CP cases it has been proven that the causative pathway starts long before delivery. ${ }^{64-66}$ Several attempts have been made in order to define normal and abnormal fetal neurological function and to develop a method of assessment of the integrity of the fetal nervous system, but still without satisfactory sensitivity. ${ }^{48,65-67}$

Fetal behavioral patterns are directly reflecting developmental and maturational processes of fetal central nervous system. ${ }^{65-67}$ What is more, studies have shown that there is continuity between fetal and neonatal neurobehavior. It has been suggested that the assessment of fetal behavior during different periods of gestation may provide valuable information about normal and abnormal brain development, and contribute to the early diagnosis of various structural or functional neurological abnormalities. ${ }^{19}$ Technological advances in ultrasonography, particularly the introduction of high quality 3D and 4D ultrasound, allowed the study of fetal anatomy in explicit detail and the real time observation of the fetal behavior. The viewing of details of the fetal face, and especially movements of mouth, eyes (facial expressions) and fingers have been made possible with the introduction of $4 \mathrm{D}$ ultrasound. ${ }^{68-71}$ KANET is the first method that attempted to use 4D ultrasound in order to assess and combine parameters of fetal behavior and form a scoring system that would assess the fetus in a comprehensive and systematic approach, in the same way that neonatologists perform a neurological assessment in newborns during the first days of their life, in order to determine their neurological status. ${ }^{33}$ KANET appears to be able to identify functional characteristics of the fetus that predict normal and abnormal neurological development and hopefully future results of the prospective multicentric studies that are taking place at the moment in the next few years it will provide more information on fetal neurology. Such information will be of great value in counseling mothers of high risk pregnancies, like for example in cases with previous child with CP and also provide valuable evidence for cases of litigation.

\section{REFERENCES}

1. Y igiter AB, Kavak ZN. Normal standards of fetal behavior assessed by four-dimensional sonography. J M atern Fetal Neonatal Med 2006 N ov; 19(11):707-721. 
Functional Test for Fetal Brain: The Role of KANET Test

2. Rees S, Harding R. Brain development during fetal life: influences of the intra-uterine environment. N eurosci L ett 2004 M ay 6;361(1-3):111-114.

3. Joseph R. Fetal brain and cognitive development. Dev Rev 1999;20:81-98.

4. Kurjak A, Carrera J M , Stanojevic M, A ndonotopo W, A zumendi $G$, Scazzocchio E, Medic M, Salihagic-Kadic A. The role of 4D sonography in the neurological assessment of early human development. Ultrasound Rev Obstet Gynecol 2004 Sep; 4(3):148-159.

5. Eidelman Al. The living fetus e dilemmas in treatment at the edge of viability. In: B lazer S, Zimmer EZ, editors. The embryo: scientific discovery and medical ethics. Basel: K arger; 2005. p 351 e70.

6. Stanojevic M, Zaputovic S, Bosnjak A P. Continuity between fetal and neonatal neurobehavior. Semin Fetal Neonatal M ed 2012 Dec;17(6):324-329.

7. Haak P, Lenski M, Hidecker MJ, Li M, Paneth N. Cerebral palsy and aging. Dev Med Child Neurol 2009 Oct;51 (Suppl 4):16-23.

8. Einspieler C, Prechtl HF. Prechtl's assessment of general movements: a diagnostic tool for the functional assessment of the young nervous system. M ent Retard Dev Disabil Res Rev 2005;11(1):61-67.

9. Salihagic-K adic A, Kurjak A, M edić M, Andonotopo W, A zumendi G. New data about embryonic and fetal neurodevelopment and behavior obtained by $3 \mathrm{D}$ and $4 \mathrm{D}$ sonography. J Perinat M ed 2005;33(6):478-490.

10. M oster D, W ilcox A J, V ollset SE, M arkestad T, LieRT. Cerebral palsy among term and postterm births. JAMA 2010 Sep; 304(9):976-982.

11. Almli CR, Ball RH, Wheeler ME. Human fetal and neonatal movement patterns: gender difference and fetal-to-neonatal continuity. Dev Psychobiol 2001 May;38(4):252-273.

12. DiPietro JA, B ronstein $M H$, Costigan $K A$, Pressmen EK, $H$ ahn CS, Painter K, Smith BA, Y i LJ. W hat does fetal movement predict about behavior during the first two years of life? Dev Phychobiol 2002 M ay;40(4):358-371.

13. DiPetro JA, Hodson DM, Costigan KA, Johnson TR. Fetal antecedents of infant temperament. Child Dev 1996 Oct; 67(5):2568-2583.

14. DiPietro JA, Costigan KA, Pressman EK. Fetal state concordance predicts infant state regulation. Early Hum Dev 2002 J un;68(1):1-13.

15. Thoman EB, Denenberg VH, Sievel J, Zeidner LP, Becker P. State organization in neonate: developmental inconsistency indicates risk for developmental dysfunction. Neuropediatrics 1981 Feb;12(1):45-54.

16. St James-R oberts I, M enon-J ohansson P. Predicting infant crying from fetal movement data: an exploratory study. Early Hum Dev 1999 Feb;54(1):55-62.

17. Einspieler C, Prechtl HFR, Ferrari F. The qualitative assessment of general movements in preterm, term and young infants-review of the methodology. Early Hum Dev 1997 Nov;50(1):47-60.

18. Precht HF. Qualitative changes of spontaneous movements in fetus and preterm infant are a marker of neurological dysfunction. Early Hum Dev 1990 Sep;23(3):151-158.

19. de V ries JI, Visser GH, Prechtl HF. The emergence of fetal behaviour. II. Quantitative aspects. Early Hum Dev 1985 Nov;12(2):99-120.
20. de V ries JI, Visser GH, Prechtl HF. The emergence of fetal behaviour. III. Individual differences and consistencies. Early Hum Dev 1988 J an; 16(1):85-103.

21. de V ries JI, Visser GH, Prechtl HF. The emergence of fetal behaviour. I. Qualitative aspects. Early Hum Dev 1982 Dec;7(4):301-322.

22. Nijhuis JG. Fetal behaviour: developmental and perinatal aspects. Oxford, Oxford U niversity Press; 1992. Chapter 9. p. 489-498.

23. Prechtl HF. State of the art of a new functional assessment of the young nervous system. A n early predictor of cerebral palsy. Early Hum Dev 1997 Nov;50(1):1-11.

24. Kurjak A, Luetic AT. Fetal neurobehavior assessed by threedimensional/four dimensional sonography. Zdrav V estn 2010 Nov;79:790-799.

25. Salihagic-K adic A, M edic M, Kurjak A, Andonotopo W, Azumendi G, Hafner T, Milenković D. Four-dimensional sonography in the assessment of fetal functional neurodevelopment and behavioral patterns. Ultrasound Rev Obstet Gynecol 2005 J un;5(2):1-15.

26. Kurjak A, Pooh R, Tikvica A. A ssessment of fetal neurobehavior by 3D/4D ultrasound. Fetal Neurol 2009:222-250.

27. Lebit DF, Vladareanu PD. The role of $4 D$ ultrasound in the assessment of fetal behaviour. M aedica (B uchar) 2011 A pr;6(2):120-127.

28. Merz E, A bramowicz JS. 3D/4D ultrasound in prenatal diagnosis: is it time for routine use? Clin Obstet Gynecol 2012 $M$ ar; $55(1): 336-351$.

29. Kurjak A, V ecek N, Hafner T, B ozek T, Funduk-Kurjak B, Ujevic B. Prenatal diagnosis: what does four-dimensional ultrasound add? J Perinat M ed 2002;30(1):57-62.

30. Kurjak A, Vecek N, Kupesic S, A zumendi G, Solak M. Four dimensional ultrasound: how much does it improve perinatal practice? In: Carrera J M, Chervenak FA, Kurjak A, editors. Controversies in perinatal medicine, studies on the fetus as a patient. New Y ork: A CRC press company, Parthenon Publishing; 2003. p 222.

31. A ndonotopo W, Stanojevic M, K urjak A, A zumendi G, Carrera $J M$. A ssessment of fetal behavior and general movements by four-dimensional sonography. U Itras R ev O bstet G ynecol 2004 J un:4(2);103-108.

32. Kurjak A, Carrera J, M edic M, A zumendi G, A ndonotopo W, Stanojevic $M$. The antenatal development of fetal behavioral patterns assessed by four-dimensional sonography. J M atern Fetal N eonatal M ed 2005 J un;17(6):401-416.

33. Kurjak A, Tikvica A, Stanojevic M, M iskovic B, A hmed B, Azumendi G, Di Renzo GC. The assessment of fetal neurobehavior by three-dimensional and four-dimensional ultrasound. J Matern Fetal Neonatal Med 2008 Oct;21(10): 675-684.

34. Kurjak A, M iskovic $B$, Stanojevic $M$, A miel-Tison $C$, A hmed $B$, A zumendi G, V asilj O, A ndonotopo W, Turudic T, SalihagicKadic $A$. N ew scoring system for fetal neurobehavior assessed by three- and four-dimensional sonography. J Perinat Med 2008;36(1):73-81.

35. Gosselin J, Gahagan S, A miel-Tison C. The A miel-Tison Neurological A ssessment at Term: conceptual and methodological continuity in the course of follow-up. Ment Retard Dev Disabil Res Rev 2005;11(1):34-51.

36. A miel-Tison C, Gosselin J, K urjak A. Neurosonography in the second half of fetal life: a neonatologist's point of view. J Perinat M ed 2006;34(6):437-446. 
37. Tomasovic S, Predojevic M . 4D ultrasound-medical devices for recent advances on the etiology of cerebral palsy. A cta I nform M ed 2011 Dec;19(4):228-234.

38. Kurjak A, A ndonotopo W, Hafner $T$, Salihagic Kadic A, Stanojevic M, Azumendi G, A hmed B, Carrera J M, Troyano J M . N ormal standards for fetal neurobehavioral devel opmentslongitudinal quantification by four-dimensional sonography. J Perinat M ed 2006;34(1):56-65.

39. Kurjak A, Stanojevic M, A ndonotopo W, Scazzocchio-Duenas E, A zumendi G, Carrera J M . Fetal behavior assessed in all three trimesters of normal pregnancy by four-dimensional ultrasonography. Croat M ed J 20050 ct;46(5):772-780.

40. Stanojevic M , Kurjak A, Salihagic-Kadic A, V asilj O, M iskovic B, Shaddad A N, A hmed B, Tomasović S. Neurobehavioral continuity from fetus to neonate. J Perinat M ed 2011 M ar;39(2):171-177.

41. Stanojevic M, Talic A, Miskovic B, Vasilj O, Shaddad AN, A hmed B, Salihagic-Kadic A, Predojevic M, Vladareanu R, Lebit $D$, et al. A $n$ attempt to standardize Kurjak's antenatal neurodevelopmental test: Osaka Consensus Statement. D onald School J Ultrasound Obstet Gynecol 2011 O ct-Dec;5:317-329.

42. Pooh RK, Pooh K. Fetal Ventriculomegaly. Donald School J Ultrasound Obstet Gynecol 2007 Oct-Dec;1(4):40-46.

43. Kurjak $A, A$ hmed $B, A$ bo- $Y$ aquab $S, Y$ ounis $M$, Saleh $H$, Shaddad A N, Vasilj O, AI Bahar AJ, M iskovic B, et al. An attempt to introduce neurological test for fetus based on $3 D$ and 4D sonography. Donald School J Ultrasound Obstet Gynecol 2008;2(4):29-24.

44. Kuno A, A kiyama $M$, Y amashiro $C$, Tanaka $H, Y$ anagihara $T$, $\mathrm{H}$ ata $\mathrm{T}$. Three-dimensional sonographic assessment of fetal behavior in the early second trimester of pregnancy. J Ultrasound M ed $2001 \mathrm{Dec} ; 20(12): 1271-1275$.

45. Koyanagi T, Horimoto $\mathrm{N}, \mathrm{M}$ aeda $\mathrm{H}, \mathrm{K}$ ukita J, M inami T, U eda $\mathrm{K}, \mathrm{N}$ akano $\mathrm{H}$. A bnormal behavioral patterns in the human fetus at term: correlation with lesion sites in the central nervous system after birth. J Child Neurol 1993 J an;8(1):19-26.

46. Kurjak A, Stanojevic M, A ndonotopo W, Salihagic-Kadic A, Carrera J M , A zumendi G. B ehavioral pattern continuity from prenatal to postnatal life- a study by four-dimensional (4D) ultrasonography. J Perinat M ed 2004;32(4):346-353.

47. Stanojevic M , Kurjak A. C ontinuity betw een F etal and N eonatal Neurobehavior. Donald School J Ultrasound Obstet Gynecol 2008 J ul-Sep;2(3):64-75.

48. Kurjak A, A bo-Y aqoub S, Stanojevic $M, Y$ igiter $A B, V$ asilj 0 , L ebit D, Shaddad A N, A hmed B, K avak ZN, M iskovic B, et al. The potential of $4 D$ sonography in the assessment of fetal neurobehavior- multicentric study in high-risk pregnancies. J Perinat M ed 2010;38(1):77-82.

49. Andonotopo W, Kurjak A, Kosuta MI. Behavior of an anencephalic fetus studied by $4 \mathrm{D}$ sonography. J M atern Fetal Neonatal M ed 2005 Feb;17(2):165-168.

50. A bo-Y aqoub S, K urjak A, M ohammed A B, Shadad A, A bdel$M$ aaboud $M$. The role of 4-D ultrasonography in prenatal assessment of fetal neurobehaviour and prediction of neurological outcome. J M atern Fetal Neonatal Med 2012 Mar;25(3):231-236.

51. Talic A, Kurjak A, A hmed B, Stanojevic M , Predojevic M , K adic AS, Di Renzo GC. The potential of 4D sonography in the assessment of fetal behavior in high-risk pregnancies. J M atern Fetal N eonatal M ed 2011 Jul;24(7):948-954.
52. M iskovic B, Vasilj O, Stanojevic M, Ivanković D, K erner M, Tikvica A. The comparison of fetal behavior in high risk and normal pregnancies assessed by four dimensional ultrasound. J M atern Fetal N eonatal M ed 2010 Dec;23(12):1461-1467.

53. A ndonotopo $W, K$ urjak $A$. The assessment of fetal behavior of growth restricted fetuses by $4 \mathrm{D}$ sonography. J Perinat Med 2006;34(6):471-478.

54. Talic A, Kurjak A, Stanojevic M, Honemeyer U, Badreldeen $A$, Direnzo GC. The assessment of fetal brain function in fetuses with ventriculomegaly: the role of the KANET test. J Matern Fetal N eonatal M ed 2012 Aug;25(8):1267-1272.

55. Kurjak A, M iskovic B, A ndonotopo W, Stanojevic M , A zumendi $G, V$ rcic H. How useful is $3 D$ and $4 D$ ultrasound in perinatal medicine? J Perinat M ed 2007;35(1):10-27.

56. Horimoto N, Koyanagi T, Maeda H, Satoh S, Takashima T, M inami T, Nakano H. Can brain impairment be detected by in utero behavioural patterns? A rch Dis Child 1993 J ul;69(1 Spec No):3-8.

57. M orokuma S, Fukushima K, Y umoto $Y, U$ chimura M , Fujiwara A, Matsumoto M, Satoh S, Nakano H. Simplified ultrasound screening for fetal brain function based on behavioral pattern. Early Hum Dev 2007 M ar;83(3):177-181.

58. Prechtl $\mathrm{HF}$, Einspieler $\mathrm{C}$. Is neurological assessment of the fetus possible? Eur J Obstet Gynecol Reprod Biol 1997 Dec;75(1): 81-84.

59. Nijhuis JG, Prechtl HF, M artin CB, B ots RS. A re there behavioral states in the human fetus? Early Hum Dev 1982;6:177-195.

60. Honemeyer $U, K$ urjak $A$. The use of K ANET test to assess fetal CNS function. First 100 cases. U ruguay: 10th W orld Congress of Perinatal M edicine; 8-11 N ovember 2011. Poster presentation P209.

61. V ladareanu R, L ebit D, Constantinescu S. U Itrasound assessment of fetal neurobehaviour in high-risk pregnancies. D onald School J Ultrasound Obstet Gynecol 2012 A pr-J un;6(2):132-147.

62. Honemeyer $U$, Talic $A$, Therwat $A$, Paulose $L$, Patidar $R$. The clinical value of KANET in studying fetal neurobehavior in normal and at-risk pregnancies. J Perinat Med $2013 \mathrm{M}$ ar; 41(2):187-197.

63. Hepper PG. Fetal behavior: why so skeptical? U Itrasound O bstet Gynecol 1996;8(3):145-148.

64. Greenwood C, N ewman S, Impey L, J ohnson A. Cerebral pal sy and clinical negligence litigation: a cohort study. BJOG 2003 Jan;110(1):6-11.

65. Strijbis EM , O udman I, van Essen $P, M$ acL ennan A H. Cerebral palsy and the application of the international criteria for acute intrapartum hypoxia. Obstet Gynecol 2006 J un;107(6):13571365.

66. de $V$ ries JI, Fong BF. Changes in fetal motility as a result of congenital disorders: an overview. U Itrasound O bstet Gynecol 2007 M ay;29(5):590-599.

67. de V ries JI, Fong BF. Normal fetal motility: an overview. Ultrasound Obstet Gynecol 2006 J un;27(6):701-711.

68. Rosier-van Dunné FM, van Wezel-M eijler $G$, B akker M P, de Groot L, Odendaal HJ, de V ries JI. General movements in the perinatal period and its relation to echogenicity changes in the brain. Early Hum Dev 2010 Feb;86(2):83-86.

69. Hata T, K anenishi K, A kiyama M, Tanaka H, Kimura K. Realtime 3-D sonographic observation of fetal facial expression. J Obstet Gynaecol Res 2005 Aug;31(4):337-340. 
70. Kozuma S, Baba K, Okai T, Taketani Y. Dynamic observation of the fetal face by three-dimensional ultrasound. Ultrasound Obstet Gynecol 1999 A pr;13(4):283-284.

71. Kurjak A, Azumendi G, A ndonotopo W, Salihagic-Kadic A. Three- and four-dimensional ultrasonography for the structural and functional evaluation of the fetal face. A m J Obstet Gynecol 2007 J an;196(1):16-28.

72. Kurjak A, Predojevic M, Kadic A S. Fetal brain function: lessons learned and future challenges of 4D sonography. Donald School J Ultrasound Obstet Gynecol 2011 A pr-J un 2011;2(5):85-92.

73. Kurjak A, Talic A, Honemeyer U, Stanojevic M, Zalud I. Comparison between antenatal neurodevelopmental test and fetal Doppler in the assessment of fetal well being. J Perinat Med 2013 J an;41(1):107-114.

74. A thanasiadis A P, M ikos T, T ambakoudis GP, Theodoridis TD, Papastergiou M, A ssimakopoulos E, Tarlatzis BC. Neurodevelopmental fetal assessment using K A NET scoring system in low and high-risk pregnancies. J M atern Fetal $\mathrm{N}$ eonatal M ed $2013 \mathrm{M}$ ar;26(4):363-368.
75. Predojević M, Talić A, Stanojević M, K urjak A, Salihagić Kadić A. A ssessment of motoric and hemodynamic parameters in growth restricted fetuses-case study. J M atern Fetal Neonatal M ed 2013 J un 20. [E pub ahead of print]

\section{ABOUT THE AUTHORS}

\section{Panagiotis Antsaklis (Corresponding Author)}

Research Fellow, First Department of Obstetrics and Gynecology University of A thens, A thens, Greece, e-mail: panosant@ gmail.com

\section{Asim Kurjak}

Professor, Department of Obstetrics and Gynecology, Rector of Dubrovnik International U niversity, Dubrovnik, Croatia

\section{Sebija Izetbegovic}

Special ist in Obstetrics and Gynecology, Director of General Hospital 'Prim. Dr A bdulah N akas', Sarajevo, B osnia and Herzegovina 